\title{
Article \\ Hand Preference in Adults' Referential Gestures during Storytelling: Testing for Effects of Bilingualism, Language Ability, Sex and Age
}

\author{
Elena Nicoladis ${ }^{1, *}$ and Safi Shirazi ${ }^{2}$ \\ 1 Department of Psychology, University of British Columbia, Kelowna, BC V1V 1V7, Canada \\ 2 Department of Psychology, University of Alberta, Edmonton, AB T6G 2E9, Canada; shirazi@ualberta.ca \\ * Correspondence: elena.nicoladis@ubc.ca; Tel.: +1-(250)-807-8461
}

check for

updates

Citation: Nicoladis, E.; Shirazi, S.

Hand Preference in Adults'

Referential Gestures during

Storytelling: Testing for Effects of

Bilingualism, Language Ability, Sex

and Age. Symmetry 2021, 13, 1776.

https://doi.org/10.3390/

sym13101776

Academic Editor:

Sebastian Ocklenburg

Received: 21 August 2021

Accepted: 20 September 2021

Published: 24 September 2021

Publisher's Note: MDPI stays neutral with regard to jurisdictional claims in published maps and institutional affiliations.

Copyright: (c) 2021 by the authors. Licensee MDPI, Basel, Switzerland. This article is an open access article distributed under the terms and conditions of the Creative Commons Attribution (CC BY) license (https:// creativecommons.org/licenses/by/ $4.0 /)$.

\begin{abstract}
Previous studies have shown that gestures are mediated by the left hemisphere. The primary purpose of this study was to test whether most gestures are also asymmetrical, i.e., produced with the right hand. We also tested four predictors of the degree of right-hand gesture use: bilingualism, language ability, sex, and age. These factors have been related to differences in the degree of language lateralization. English monolinguals, French-English bilinguals, and French monolinguals watched a cartoon and told the story back. For the gestures they produced while speaking, we calculated the percentage produced with the right hand. As predicted, the majority of gestures were right-handed $(60 \%)$. Bilingualism, language ability, and age were not significantly related to hand choice in either English or French. In English, males tended to produce more right-handed gestures than females. These results raise doubts as to whether hand preference in gestures reflects speech lateralization. We discuss possible alternative explanations for a right-hand preference.
\end{abstract}

Keywords: lateralization; gestures; hand preference; bilingualism; proficiency; age; sex

\section{Introduction}

Approximately $90 \%$ of the population is right-handed; this means that they prefer to use their right hand over their left hand when performing asymmetrical skilled movements, such as using tools [1-3]. Previous researchers have shown a correspondence between righthandedness and left-hemisphere specialization in the recognition and recall of sequential information, as well as motor planning [2-4]. Handedness also shows correspondence with language lateralization, with the majority of the population showing left-hemisphere dominance for processing language [1,5-8].

Left lateralization has also been found for both the production and comprehension of gestures [7,9-12]. Gestures refer to communicative movements of hand and arms, such as pointing or showing the size of the fish that got away [13,14]. One study found that common neural circuits and areas are activated, such as Broca's area, when comprehending symbolic gestures such as pantomimes (actions such as threading a needle) and spoken language [12]. Similarly, a Positron Emission Tomography (PET) scan study found that when watching meaningful actions, such as iconic gestures (i.e., gestures that resemble the referent, such as a gesture showing the size of the fish that got away), participants had a strong left hemispheric engagement [10]. Gestures may tend to be left-lateralized because of their connection to speech. Speech and manual gesture are closely interconnected in their development [15], timing in production [16], and loss due to brain damage [17,18]. Given these strong interconnections between speech and gestures, McNeill argued that instead of speech, researchers should study the speech-gesture system [14].

Since motor control of the right side of the body is mediated by the left hemisphere, we could therefore predict that people would gesture more with their right hands than their left hands. Several studies have, indeed, shown that people often show a right-handed bias 
while gesturing, in both children [19,20] and adults [7,21] (although not always [22,23]). For example, Saucier and Elias observed adult dyads during natural conversation and found that the participants used significantly more right-handed gestures than left-handed gestures [21].

Some studies have challenged the hypothesis that gesture production is primarily left-lateralized [24-27]. Based on gesture production in split-brain patients, Kita and Lausberg found evidence that the non-dominant-for-language right hemisphere could generate gestures as well as the dominant left hemisphere [25]. Similarly, another study found that people with right-hemisphere damage produced few gestures, while people with left-hemisphere damage produced a lot of gestures [24]. Taken together, these results suggest that the right hemisphere can generate referential gestures, at least among people with brain damage.

The primary purpose of the present study was to replicate the results of previous studies showing a right-hand preference in gesturing [21]. Such a preference could be indicative of left-lateralization of speech-gesture functions. If so, then factors that are related to the degree of left lateralization of speech could also impact the degree of righthand preference in gestures. A secondary purpose of this study was to test four of these factors: bilingualism, language ability, age, and sex. We discuss each of these factors in turn.

\subsection{Language Lateralization and Bilingualism}

Some studies have shown that bilinguals have less left lateralization for language (more bilateral processing) than monolinguals [28-32]; see also [33]. However, some studies have shown no hemispheric differences in language lateralization for bilinguals and monolinguals $[28,34,35]$. One possible reason for the variability of results is that the age of acquisition of a second language is related to language lateralization $[28,30,33,36]$. Specifically, based on a meta-analysis of 66 studies, Hull and Vaid argued that if a second language is acquired prior to the age of six, bilinguals are likely to show greater bilateral processing than monolinguals [28]; see supporting evidence in [36]. If a second language is acquired after the age of six, bilinguals are likely to show greater left-hemisphere lateralization than monolinguals [28].

In the present study, we predicted that bilinguals would produce fewer right-handed gestures than monolinguals in both English and French, particularly if they acquired their two languages early in life.

\subsection{Language Lateralization and Language Proficiency}

While researchers have often attributed lateralization patterns in bilinguals to the age of acquisition [28], the age of acquisition is highly correlated to language proficiency [37]; see also the discussion in [30]. The degree of left-hemisphere lateralization has been shown to be related to language proficiency in children [38,39].

Further indirect evidence of a correspondence between lateralization and language proficiency comes from studies involving children and hand preference in gesturing. Infants and toddlers show a right-hand preference in pointing [19,40,41]. One study found a correlation between receptive vocabulary scores and degree of right-hand preference in pointing among 10- to 12-month-old infants [41]. Additionally, Cochet et al. observed that children showed a high degree of right-handed gestures during a lexical spurt development period [19].

A study with preschoolers tested how two measures of language proficiency were related to the percentage of right-hand referential gestures used while telling a story [42]: vocabulary scores and word types (i.e., the number of unique words produced to tell the story). Referential gestures refer to the categories of both iconic gestures and abstract points (e.g., pointing to the left to indicate where a story character had gone). They found that vocabulary scores were a negative predictor and word types were a positive predictor of the percentage of right-hand gestures produced. The authors argued that 
these results suggested that the degree of right-hand preference in gestures was related to the constructive lexical access. In other words, right-handed gestures were particularly likely to be produced when speakers were accessing appropriate words to convey their message (hence, a positive relationship with word types) when they did not necessarily have conventional words in their vocabulary to express that message (hence, a negative relationship with vocabulary scores).

In the present study, as in [42], we also included two measures of language ability: vocabulary and word types. If the results of [42] generalize to adults, we should also find that vocabulary is a negative predictor and words types a positive predictor of the degree of right-hand gesture production in English and French.

\subsection{Language Lateralization and Sex}

Some studies have found that males are more left-lateralized for language than females [43-45]. Kansaku et al. found that females showed no significant lateralization in any of the three temporal gyri, but males showed significant left hemisphere lateralization in the superior temporal gyrus (STG) and the middle temporal gyrus (MTG) [44]. Yu et al. showed similar sex differences in a neuroimaging study involving children between 4 and 18 years of age [45]. It is important to keep in mind that some studies have found no sex differences in language lateralization [46].

Consistent with studies showing greater left lateralization among males than females, Saucier and Elias found that males produced significantly more right-handed gestures than females in naturalistic conversations [21]. In the present study, we predicted that we, too, would find that males produce more right-handed gestures than females in both English and French.

\subsection{Language Lateralization and Age}

The participants in our study ranged between 18 and 75 years of age. Previous studies have suggested that there are age-related changes in the lateralization of language $[8,47]$. In an fMRI study, Szaflarski et al. found that older adults had greater bilateral language processing than younger adults and children [8]. In the task, participants named verbs associated with a presented noun, and this resulted in the activation of language-related brain areas. Of interest, the researchers found that language lateralization decreased from the ages of 25-70. In other words, language became increasingly bilateral with age.

In the present study, we predicted that the older the participants, the fewer righthanded gestures they would use in both English and French.

\subsection{This Study}

The primary hypothesis in this study was that participants would produce more unimanual referential gestures with their right hands than their left hands (as in [21]).

The secondary purpose of this study was to test four factors that might affect the degree of right-hand gesture use: bilingualism, language ability, sex, and age. We predicted that bilinguals would use fewer right-hand gestures than monolinguals, particularly if they learned the language before the age of six [28]. As for language ability, we predicted that we would find that word types were a positive predictor and vocabulary scores a negative predictor of the degree of right-hand preference in gesturing, as found for preschoolers [42]. For sex, we predicted that males would produce more right-handed gestures than females, as in [21]. Finally, we predicted that the older the participants, the fewer right-handed gestures they would produce.

The data for this study were originally collected to address different research questions to the current ones, including the timing of gestures to speech [14], how gesture use relates to language proficiency [48], and how the use of gestures relates to working memory [49]. None of the present analyses reproduce those that were carried out previously. 


\section{Materials and Methods}

\subsection{Participants}

Before collecting data, ethical approval for the methods of this study was obtained from the Research Ethics Board of the University of Alberta (Pro00010721, Pro00044533, Pro00048526). In total, 37 English monolinguals, 11 French monolinguals, and 67 bilinguals (33 spoke English as a first language; 34 French as a first language) participated in this study. Six additional English monolinguals were interviewed, but their data were not included in the present analyses because they did not produce any unimanual gestures. Table 1 summarizes some of the participants' background information. The English monolinguals and the bilinguals were all residing in an English-majority-language part of Canada. The French monolinguals lived close to Montreal, Quebec, a French-majority-language part of Canada. The English-first-language (English L1) bilinguals had a fairly homogenous language background: they all learned English first at home and learned French at school, usually in French immersion programs starting at around 5-6 years of age. We therefore expected the English L1 bilinguals to resemble monolinguals in their hand preference for gesturing (see [28]). The French-first-language (French L1) bilinguals had a more heterogenous background: all had learned French as at least one of their first languages at home and had some exposure to English early in life. For some of the French L1 bilinguals' $(\mathrm{N}=14)$, exposure to English was both early and sustained, so they could be categorized as simultaneous bilinguals. For the others, the sustained exposure to English started later, usually in school. There was no outstanding difference between the simultaneous French L1 bilinguals and the other French L1 bilinguals on any of the measures in this study. We therefore treated them as a single group. The French L1 bilinguals might show less right-hand preference in gesturing than the other language groups (see [28]).

Table 1. Background demographical information on participants.

\begin{tabular}{llllll}
\hline & Monolinguals & \multicolumn{3}{l}{ Bilinguals } \\
\cline { 2 - 6 } & French & English & English L1 & French L1 & All \\
\hline $\mathrm{N}$ & 11 & 37 & 33 & 34 & 67 \\
Avg (SD) age & $37.5(9.4)$ & $24.8(8.7)$ & $23.1(5.5)$ & $28.4(9.8)$ & $25.7(8.2)$ \\
Age range & $24-59$ & $18-75$ & $18-34$ & $18-52$ & $18-52$ \\
\#Women/men & $10 / 1$ & $25 / 15$ & $25 / 8$ & $23 / 10$ & $48 / 18$ \\
\hline
\end{tabular}

The four language groups differed significantly in age, $F(3,110)=9.35, p<0.001$, $\eta^{2}=0.206$. Post hoc Tukey tests showed that the French monolinguals were significantly older than the English monolinguals $(p<0.001)$ and the English L1 bilinguals $(p<0.001)$, and the French L1 bilinguals $(p=0.01)$. The difference in age between the two bilingual groups approached significance $(p=0.06)$. No other differences between groups approached significance $(p \geq 0.27)$. These age differences between the groups reinforce the importance of including age as a variable in the following analyses.

\subsection{Materials}

To elicit gestures from participants, they all watched two four-minute clips of Pink Panther cartoons. In one clip, the Pink Panther tries to get rid of a cuckoo bird from a cuckoo clock that kept trying to wake him up. In the other clip, the Pink Panther tries to pilot an experimental jet and is taken for a wild ride by the jet.

To assess vocabulary in English, we used the Peabody Picture Vocabulary Test-III (PPVT), version A [50]. We obtained English vocabulary scores for 26 monolinguals, all 33 English L1 bilinguals, and 24 French L1 bilinguals. To assess vocabulary in French, we used the Echelle de Vocabulaire en Images Peabody (EVIP) [51]. We obtained French vocabulary scores for 31 English L1 bilinguals, 24 French L1 bilinguals, and none of the monolinguals. 


\subsection{Procedure}

Within a testing session, the participants watched the two Pink Panther clips in order with no break. They were then invited to tell the story back to a native or very fluent speaker of the target language. The interviewer explained that $s /$ he had not seen the cartoon before and wanted to know what had happened. The participants' stories were videotaped for later transcription and coding. The bilinguals did this twice: once in English and once in French. The two language sessions for the bilinguals took place on two different days, usually about a week apart.

For the participants who took the vocabulary tests, the tests were administered following the story retelling, according to the examiner's manuals. For the bilinguals, the PPVT was administered in the English session and the EVIP in the French session. We report standardized scores here.

\subsection{Coding and Analysis}

The participants' stories were transcribed in orthographic words. For each participant, we coded the word types, that is, the number of unique words used to tell the story. We coded the participants' referential gestures, including both iconic gestures (i.e., gestures that resemble the referent, such as moving one's hands as if throwing to signify throwing), and deictic gestures (i.e., gestures that indicate a stable location in space, such as the imaginary location of the Pink Panther's house) [14]. The referential gestures were coded for which hand(s) were used in the movement. The main dependent variable for this study is the percentage of right-handed referential gestures out of the total unimanual referential gestures.

Two English L1 bilinguals and one French L1 bilingual produced no unimanual referential gestures in English. The French video of one English L1 bilingual was erased due to an experimenter's error. Additionally, one English L1 bilingual and one French L1 bilingual did not produce any unimanual referential gestures in French. The data from these participants are included in the analyses whenever possible.

Because the bilinguals participated in both English and French, we could not include the bilinguals and both groups of monolinguals in a single analysis (i.e., the bilinguals' data in English and French are not independent). We therefore analyzed the English and the French data separately. This analytic approach also allowed us to check for cross-linguistic generalizability. We expected to find the same results in both languages.

\section{Results}

\subsection{English}

In English, the participants produced an average of $60.1 \%(\mathrm{SD}=29.9 \%)$ referential gestures with their right hands. Table 2 summarizes the results by language groups in English. There were no significant differences between the three language groups on any measures in English: the PPVT, $F(2,77)=0.67, p=0.52, \eta^{2}=0.017$, word types, $F(2,101)=1.96, p=0.15, \eta^{2}=0.037$, or the number of unimanual gestures. $F(2,101)=0.45$, $p=0.64, \eta^{2}=0.009$.

Contrary to predictions, there were no significant differences between language groups on the percentage of right-handed gestures, $F(2,93)=0.61, p=0.61, \eta^{2}=0.019$. A onesample $t$-test revealed that the participants' percentage of right-hand gestures differed significantly from $50 \%, t(83)=2.83, p=0.006$. 
Table 2. Average (SD) for study variables in English.

\begin{tabular}{|c|c|c|c|c|}
\hline & \multirow{2}{*}{$\begin{array}{l}\text { Monolinguals } \\
\text { English }\end{array}$} & \multicolumn{3}{|l|}{ Bilinguals } \\
\hline & & English L1 & French L1 & All \\
\hline PPVT $^{1}$ & $115.6(11.5)$ & $118.6(10.8)$ & $115.4(10.8)$ & $117.3(10.8)$ \\
\hline $\mathrm{EVIP}^{2}$ & - & $104.7(13.2)$ & $117.5(10.2)$ & $110.1(13.5)$ \\
\hline Word types ${ }^{3}$ & $229.6(93.3)$ & $211.0(79.9)$ & $200.5(75.0)$ & $205.6(93.3)$ \\
\hline \#Gestures 4 & $37.2(36.5)$ & $30.6(27.0)$ & 33.8 (21.1) & $32.7(24.0)$ \\
\hline$\% \mathrm{RH}^{5}$ & $56.7 \%(32.8 \%)$ & $59.4 \%(31.2 \%)$ & $61.2 \%(28.4 \%)$ & $60.4 \%(30.0 \%)$ \\
\hline
\end{tabular}

${ }^{1}$ PPVT $=$ Peabody Picture Vocabulary Test; ${ }^{2}$ EVIP $=$ Echelle de vocabulaire en images Peabody; ${ }^{3}$ Word types $=$ number of unique words used to tell the story; ${ }^{4}$ \# Gestures $=$ the number of unimanual referential gestures produced; $\%$ RH $=$ the percentage of unimanual gestures produced with the right hand.

As there were no differences between bilinguals and monolinguals, we included both in the following regression analyses. We used sex, age, and word types as predictors of the percentage of right-handed gestures in a linear multiple regression. We only obtained PPVT scores for 83 participants, so we ran that regression separately. Table 3 summarizes the results. The overall regression without the PPVT approached significance, $F(3,95)=2.36$, $p=0.077, \mathrm{R}^{2}=0.07$, and with the PPVT, $F(4,74)=2.00, p=0.10, \mathrm{R}^{2}=0.10$. In both analyses, sex and age either approached or attained significance. The negative beta value for sex means that males tended to produce more right-handed gestures than females. The negative beta value with age means that younger participants produced more righthanded gestures than older participants. While the language measures never approached significance, note that the beta values are negative, meaning that the higher the language abilities, the more left-handed gestures.

Table 3. Summary of multiple linear regression results in English, without and with PPVT as predictor.

\begin{tabular}{|c|c|c|c|c|}
\hline & \multicolumn{2}{|c|}{ Without PPVT ${ }^{3}$ as Predictor } & \multicolumn{2}{|c|}{ With PPVT ${ }^{3}$ as Predictor } \\
\hline & Beta-Value & $p$-Value & Beta-Value & $p$-Value \\
\hline Sex ${ }^{1}$ & -0.179 & 0.079 & -0.230 & 0.04 \\
\hline Age & -0.167 & 0.10 & -0.203 & 0.076 \\
\hline Word types ${ }^{2}$ & -0.137 & 0.17 & -0.120 & 0.31 \\
\hline PPVT $^{3}$ & & & -0.064 & 0.59 \\
\hline
\end{tabular}

${ }^{1}$ For sex, $1=$ female and $0=$ male; ${ }^{2}$ Word types = number of unique words used to tell the story; ${ }^{3}$ PPVT $=$ Peabody Picture Vocabulary Test.

To follow up on the sex difference, the females averaged $55.6 \%(\mathrm{SD}=30.4 \%)$ of their gestures being right-handed, while the males averaged $66.5 \%(\mathrm{SD}=30.5 \%)$ being righthanded. The females' right-hand preference did not differ significantly from no preference (i.e., $50 \%$ ) on a one-sample $t$-test, $t(68)=1.54, p=0.13$. The males' right-hand preference was significantly different from $50 \%, t(31)=3.02, p=0.005$.

\subsection{French}

In French, the participants produced an average of $60.5 \%$ (SD $=30.9 \%)$ of their referential gestures with their right hands. Table 4 summarizes the results for French. The difference between groups approached significance for word types, $F(2,74)=2.87, p=0.06$, $\eta^{2}=0.072$. The French L1 bilinguals tended to produce more different words than the other two groups. There was a significant difference by group in the number of gestures produced, $F(2,74)=3.54, p=0.03, \eta^{2}=0.088$. As can be seen in Table 4 , both bilingual groups tended to produce more unimanual gestures than the monolinguals. In post hoc Tukey tests, only the difference between the French L1 and the monolinguals reached significance $(p=0.03)$. We only obtained EVIP scores for bilinguals (see Table 2 for descriptive data). The French L1 bilinguals had significantly higher EVIP scores than the English L1 bilinguals, $F(1,55)=15.63, p<0.001, \eta^{2}=0.221$. 
Table 4. Average (SD) for study variables in French.

\begin{tabular}{lllll}
\hline & Monolinguals & Bilinguals & & \\
\cline { 2 - 5 } & French & English L1 & French L1 & All \\
\hline Word types $^{1}$ & $187.3(62.5)$ & $181.7(67.5)$ & $229.0(101.1)$ & $206.1(89.0)$ \\
\#Gestures $^{2}$ & $11.1(10.7)$ & $22.3(15.0)$ & $27.3(21.2)$ & $24.9(18.5)$ \\
\%RH $^{3}$ & $65.2 \%(36.3 \%)$ & $59.3 \%(31.4 \%)$ & $60.1 \%(29.4 \%)$ & $59.7 \%(30.1 \%)$ \\
\hline
\end{tabular}

${ }^{1}$ Word types = number of unique words used to tell the story; ${ }^{2} \#$ Gestures $=$ the number of unimanual referential gestures produced; ${ }^{3} \% \mathrm{RH}=$ the percentage of unimanual gestures produced with the right hand.

As for the percentage of right-handed gestures, contrary to predictions but consistent with our English results, there was no significant difference between the groups, $F(2,72)=0.15, p=0.86, \eta^{2}=0.004$. A one-sample $t$-test showed that the percentage of right-handed gestures did differ significantly from $50 \%$ in French, $t(73)=3.22, p=0.002$.

Since there was no significant difference between bilinguals and monolinguals in the percentage of right-handed gestures, we included both together in the following regression analyses. We included sex, age, and word types as predictors of gesture use in all the analyses. We only obtained EVIP scores for 55 participants (all bilingual), so we ran that regression separately. Table 5 summarizes the regression results for the percentage of righthanded gestures in French. The overall regressions were not significant, either without the EVIP as a predictor, $F(3,71)=0.47, p=0.71, \mathrm{R}^{2}=0.02$, or with the EVIP as a predictor, $F(4,52)=0.36, \mathrm{p}=0.84, \mathrm{R}^{2}=0.03$. As can be seen in Table 5 , no individual predictor approached significance.

Table 5. Summary of multiple linear regression results in French, without and with EVIP as predictor.

\begin{tabular}{|c|c|c|c|c|}
\hline & \multicolumn{2}{|c|}{ Without EVIP ${ }^{3}$ as Predictor } & \multicolumn{2}{|c|}{ With EVIP ${ }^{3}$ as Predictor } \\
\hline & Beta-Value & $p$-Value & Beta-Value & $p$-Value \\
\hline $\operatorname{Sex}^{1}$ & -0.087 & 0.47 & -0.003 & 0.98 \\
\hline Age & 0.108 & 0.37 & 0.061 & 0.69 \\
\hline Word types ${ }^{2}$ & -0.034 & 0.78 & -0.144 & 0.35 \\
\hline EVIP $^{3}$ & & & 0.121 & 0.46 \\
\hline
\end{tabular}

${ }^{1}$ For sex, $1=$ female and $0=$ male; ${ }^{2}$ Word types $=$ number of unique words used to tell the story; ${ }^{3}$ EVIP $=$ Echelle de vocabulaire en images Peabody.

While sex did not even approach significance as a predictor for French, we nonetheless present the results by sex compared to chance to parallel our analyses in English. The females averaged $59.0 \%(\mathrm{SD}=32.2 \%)$, differing significantly from $50 \%$ on a one-sample $t$-test, $t(56)=2.10, p=0.04$. The males averaged $65.5 \%(\mathrm{SD}=26.6 \%)$ right-handed gestures, differing significantly from $50 \%, t(17)=2.48, p=0.02$.

\section{Discussion}

The primary purpose of this study was to test whether adults produced more righthanded referential gestures than left-handed gestures when telling a story. As predicted, participants produced an average of around $60 \%$ of their unimanual gestures with their right hand in both French and English. In other words, they showed a right-hand preference in gesturing. These results support previous evidence showing that adults and children tend to gesture more with their right hand than their left hand [7,21,52].

Previous studies have argued that the right-hand preference in gestures is due to the left-hemisphere lateralization of speech and gestures [21]. Indeed, there is independent evidence to suggest left-hemisphere dominance in the processing of both speech and gestures [7,9-12]. A secondary purpose of the present study was to test four factors that are related to the degree of language lateralization: bilingualism, language proficiency, sex, and age. We reasoned that if the hand preference in gesturing follows the same patterns as language lateralization, we might find that bilinguals produced fewer right-hand gestures than monolinguals. However, there was no difference in right-handed gestures among 
bilinguals and monolinguals in either French or English. The English L1 bilinguals had all started to learn French between the ages of 5-6 years. Regarding the idea that the age of acquisition made a difference, we hypothesized that the French L1 bilinguals would produce fewer right-handed gestures than the English L1 bilinguals or the monolinguals. However, we found no difference between the two bilingual groups.

As for language proficiency, following [42], we included two measures of language proficiency: word types and vocabulary scores. We predicted that word types would be a positive predictor and vocabulary a negative predictor, as in [42]. Our results showed that language proficiency was not a significant predictor of right-handed gestures in either English or French. The bilinguals in [42] were much more proficient in one language than the other. In our study, the bilinguals were highly proficient in both languages. Future studies can include more unbalanced bilinguals as another experimental group to test for the possibility that hand preference in gesture use is related to lexical access when vocabulary resources are weak [42].

Some previous studies have found that males are more left-lateralized for language than females [43-45]. We therefore predicted that males would produce more right-handed gestures than females. As predicted, males in this study did tend to produce more righthanded gestures than females in English. The English results replicate those of Saucier and Elias [21]. However, the sex difference was not observed in French, although the averages were in the predicted direction. One possible reason for this result is that we had few male participants in the French groups. Future studies can include larger samples of both male and female participants to test this interpretation.

In the present study, the participants ranged in age between 18 and 75 years. Previous studies have shown age-related changes in language lateralization, with decreasing lefthemisphere lateralization with increasing age [8,47]. We predicted that in this study, we would observe fewer right-handed gestures with the increasing age of participants. We found that, in English, age did border on significance in the predicted direction. However, the same pattern was not observed in French. Most of our participants were in their 20s, so future studies could more systematically include elderly participants to better test for possible effects of age.

Taken together, there was remarkably weak support for any four of the variables significantly predicting the percentage of right-handed gestures, at least consistently across languages. We already pointed out that there may be characteristics of our particular sample that could have affected the results. Nonetheless, these results raise the possibility that hand preference in gesturing may not reflect language lateralization in adults at all. Previous research has made similar arguments, based on gesture production among people with brain damage [24-27]. If either hemisphere can generate gestures, why, then do neurotypical people tend to gesture with their right hands ([21]; this study)? We discuss three other variables that could be related to people's hand preference in gesturing: handedness for tool use, the content of what is being talked about, and constructive lexical access.

One possible reason to explain why people tend to prefer to gesture with their right hand is because they frequently use their right hand in everyday life to interact with objects [1-3]. If so, then the strength of handedness for tool use would be correlated with the degree of hand preference in gesturing. In this study, we did not measure handedness in these participants, because the data were collected for other purposes. For the purposes of the predictions for this study, the lack of this information should have made little difference: previous studies have shown that approximately $94 \%$ of the general population is left-lateralized for language, regardless of handedness [53]. Furthermore, the median degree of handedness in the population is around 80\% [54], in marked contrast to the $60 \%$ right-hand preference found in gesturing in this study. However, in order to test whether hand preference in object interactions is related to hand preference in gesture use, future studies should include measures of handedness. While this explanation is possible, it seems unlikely given research that shows that women tend to be more right-handed 
than men [55] and men are more likely to be left-handed than women [56]. This pattern of handedness is contrary to the trends we observed in this study, with males tending to use their right hand more in producing gestures than females. Nevertheless, it will be important to include measures of individuals' handedness in future studies.

Another possibility for the right-hand preference in referential gestures is that hand choice is related to the content of what people are talking about [26]. One study elicited gestures by asking people to speak about animations [27]. They found that speakers' hand choices in gesturing were related to the side of the screen that the participants had observed the action. People generally show a right visual field advantage when viewing tools [57] or written language [58]. People may tend to focus visually more on the right side of the screen when they know they are going to have to speak. If so, then they might gesture more with their right hands. Future research can test this possibility by including eye tracking and/or the systematic assignment of stimuli on the right or left side of the screen.

One other possibility for a right-hand preference in gesturing is that gesturing with the right hand aids lexical access. Recall that [42] argued that a right-hand preference in referential gesturing was related to accessing words for production in preschool children. They based this argument on their results showing that word types while telling a story was a positive predictor of right-hand gesture preference, while vocabulary was a negative predictor. We did not replicate those findings in the present study with adults. However, since all of our participants were highly fluent in either English, French, or both, it is possible that these language measures did not tap lexical access difficulties in these participants. If so, then future studies can systematically test the relationship between hand preference and task difficulty.

\section{Conclusions}

In conclusion, we showed that adults show a right-hand preference in producing referential gestures while telling a story. While this preference could correspond to a higher degree of gesture lateralization in the left hemisphere, our other analyses raised doubts about that conclusion. Specifically, bilingualism, language proficiency, sex, and age did not consistently predict the degree of right-hand preference. Previous studies have shown that all four of these factors are associated with the degree of language lateralization. We argued that variables other than lateralization might explain adults' right-hand preference in gesturing.

Author Contributions: Conceptualization, E.N. and S.S.; methodology, E.N.; coding, S.S.; formal analysis, E.N.; writing—original draft preparation, S.S.; writing—review and editing, E.N.; funding acquisition, E.N. All authors have read and agreed to the published version of the manuscript.

Funding: This research was funded by a Discovery Grant to E.N. from the Natural Sciences and Engineering Research Council of Canada, grant number 2018-04978.

Institutional Review Board Statement: The study was conducted according to the guidelines of the Declaration of Helsinki, Canadian Tricouncil ethical policies and approved by the Research Ethics Board of the University of Alberta (Pro\#00010721, approved 23 December 2007, Pro\#00010221, approved 5 December 2009, and Pro\#00048526, approved 29 May 2017).

Informed Consent Statement: Written, informed consent was obtained from all participants involved in the study.

Data Availability Statement: The data analyzed in this manuscript are publicly available at: DOI 10.17605/OSF.IO/R3MWT.

Acknowledgments: Thanks to Jasmine Aziz, Carrie Jensen, Nathalie Savoie, and Lisa Smithson for recruitment, testing, and transcription of data.

Conflicts of Interest: The authors declare no conflict of interest. 


\section{References}

1. Cochet, H. Manual asymmetries and hemispheric specialization: Insight from developmental studies. Neuropsychology 2016, 93, 335-341. [CrossRef] [PubMed]

2. Kinsbourne, M. Development of cerebral lateralization in children. In Handbook of Clinical Child Neuropsychology; Reynolds, C.R., Fletcher-Janzen, E., Eds.; Springer: New York, NY, USA, 2009; pp. 47-66.

3. Serrien, D.J.; Ivry, R.B.; Swinnen, S.P. Dynamics of hemispheric specialization and integration in the context of motor control. Nat. Rev. Neurosci. 2006, 7, 160-166. [CrossRef] [PubMed]

4. Isaacs, K.L.; Barr, W.B.; Nelson, P.K.; Devinsky, O. Degree of handedness and cerebral dominance. Neurology 2006, 66, 1855-1858. [CrossRef]

5. Corballis, M.C. The evolution and genetics of cerebral asymmetry. Phil. Trans. Roy. Soc. B Bio Sci. 2009, 364, 867-879. [CrossRef]

6. Gut, M.; Urbanik, A.; Forsberg, L.; Binder, M.; Rymarczyk, K.; Sobiecka, B.; Kozub, J.; Grabowska, A. Brain correlates of right-handedness. Acta Neurobio. Experim. 2007, 67, 43-51.

7. Kimura, D. Manual activity during speaking, I. Right-handers, II. Left-handers. Neuropsychologia 1973, 11, 45-55. [CrossRef]

8. Szaflarski, J.P.; Holland, S.K.; Schmithorst, V.J.; Byars, A.W. fMRI study of language lateralization in children and adults. Hum. Brain Map 2006, 27, 202-212. [CrossRef] [PubMed]

9. Biduła, S.P.; Króliczak, G. Structural asymmetry of the insula is linked to the lateralization of gesture and language. Eur. J. Neurosci. 2015, 41, 1438-1447. [CrossRef]

10. Decety, J.; Grèzes, J.; Costes, N.; Perani, D.; Jeannerod, M.; Procyk, E.; Grassi, F.; Fazio, F. Brain activity during observation of actions. Influence of action content and subject's strategy. Brain 1997, 120, 1763-1777. [CrossRef]

11. Moll, J.; de Oliveira-Souza, R.; Passman, L.J.; Cunha, F.C.; Souza-Lima, F.; Andreiuolo, P.A. Functional MRI correlates of real and imagined tool-use pantomimes. Neurology 2000, 54, 1331-1336. [CrossRef]

12. $\mathrm{Xu}$, J.; Gannon, P.J.; Emmorey, K.; Smith, J.F.; Braun, A.R. Symbolic gestures and spoken language are processed by a common neural system. Proc. Natl. Acad. Sci. USA 2009, 106, 20664-20669. [CrossRef] [PubMed]

13. Kita, S. How representational gestures help speaking. In Language and Gesture; McNeill, D., Ed.; Cambridge University Press: Cambridge, UK, 2000; pp. 162-185.

14. McNeill, D. Hand and Mind: What Gestures Reveal about Thought; University of Chicago Press: Chicago, IL, USA, 1992.

15. Dick, A.S.; Goldin-Meadow, S.; Solodkin, A.; Small, S.L. Gesture in the developing brain. Dev. Sci. 2011, 15, 165-180. [CrossRef]

16. Graziano, M.; Nicoladis, E.; Marentette, P. How referential gestures align with speech: Evidence from monolingual and bilingual speakers. Lang. Learn. 2020, 70, 266-304. [CrossRef]

17. Glosser, G.; Wiener, M.; Kaplan, E. Communicative gestures in aphasia. Brain Lang. 1986, 27, 345-359. [CrossRef]

18. Akhavan, N.; Göksun, T.; Nozari, N. Integrity and function of gestures in aphasia. Aphasiology 2018, 32, 1310-1335. [CrossRef]

19. Cochet, H.; Jover, M.; Vauclair, J. Hand preference for pointing gestures and bimanual manipulation around the vocabulary spurt period. J. Exptl. Child Psych. 2011, 110, 393-407. [CrossRef]

20. Vauclair, J.; Imbault, J. Relationships between manual preferences for manipulative actions and for pointing gestures in infants and toddlers. Dev. Sci. 2009, 12, 1060-1069. [CrossRef]

21. Saucier, D.M.; Elias, L.J. Lateral and sex differences in manual gesture during conversation. Lateral 2001, 6, 239-245. [CrossRef]

22. Argyriou, P.; Mohr, C.; Kita, S. Hand matters: Left-hand gestures enhance metaphor explanation. J. Exp. Psych. Lang. Mem. Cog. 2017, 43, 874-886. [CrossRef]

23. Kita, S.; de Condappa, O.; Mohr, C. Metaphor explanations attenuates the right-hand preference for depictive co-speech gestures that imitate actions. Brain Lang. 2007, 101, 185-197. [CrossRef]

24. Hogrefe, K.; Rein, R.; Skomroch, H.; Lausberg, H. Co-speech hand movements during narrations: What is the impact of right vs. left hemisphere brain damage? Neuropsychology 2016, 93, 176-188. [CrossRef] [PubMed]

25. Kita, S.; Lausberg, H. Generation of co-speech gestures based on spatial imagery from the right-hemisphere: Evidence from split-brain patients. Cortex 2008, 44, 131-139. [CrossRef]

26. Lausberg, H.; Cruz, R.F.; Kita, S.; Zaidel, E.; Ptito, A. Pantomime to visual presentation of objects: Left hand dyspraxia in patients with complete callosotomy. Brain 2003, 126, 343-360. [CrossRef]

27. Lausberg, H.; Kita, S. The content of the message influences the hand choice in co-speech gestures and in gesturing without speaking. Brain Lang. 2003, 86, 57-69. [CrossRef]

28. Hull, R.; Vaid, J. Bilingual language lateralization: A meta-analytic tale of two hemispheres. Neuropsychology 2007, 45, 1987-2008. [CrossRef] [PubMed]

29. Hull, R.; Vaid, J. Laterality and language experience. Lateral 2006, 11, 436-464. [CrossRef]

30. Hull, R.; Vaid, J. Clearing the cobwebs from the study of the bilingual brain: Converging evidence from laterality and electrophysiological research. In Handbook of Bilingualism: Psycholinguistic Approaches; Kroll, J., de Groot, A.M.B., Eds.; Oxford University Press: London, UK, 2005; pp. 480-496.

31. Park, H.R.; Badzakova-Trajkov, G.; Waldie, K.E. Language lateralisation in late proficient bilinguals: A lexical decision fMRI study. Neuropsychology 2012, 50, 688-695. [CrossRef] [PubMed]

32. Peng, G.; Wang, W.S. Hemisphere lateralization is influenced by bilingual status and composition of words. Neuropsychology 2011, 49, 1981-1986. [CrossRef]

33. Paradis, M. Neurolinguistic Aspects of Bilingualism; John Benjamins: Amsterdam, The Netherlands, 2004. 
34. Soares, C. Converging evidence for left hemisphere language lateralization in bilinguals. Neuropsychology 1982, $20,653-659$. [CrossRef]

35. Soares, C.; Grosjean, F. Left hemisphere language lateralization in bilinguals and monolinguals. Percept. Psychophys. 1981, 29, 599-604. [CrossRef]

36. Mergen, F.; Kuruoglu, G. Hemispheric lateralization of words in Turkish-English bilinguals and Turkish monolinguals. Ling. J. 2018, 12, 97-107.

37. Archila-Suerte, P.; Zevin, J.; Bunta, F.; Hernandez, A.E. Age of acquisition and proficiency in a second language independently influence the perception of non-native speech. Biling Lang. Cog. 2012, 15, 190-201. [CrossRef]

38. Holland, S.K.; Vannest, J.; Mecoli, M.; Jacola, L.M.; Tillema, J.M.; Karunanayaka, P.R.; Byars, A.W. Functional MRI of language lateralization during development in children. Intl. J. Audio 2007, 46, 533-551. [CrossRef] [PubMed]

39. Ressel, V.; Wilke, M.; Lidzba, K.; Lutzenberger, W.; Krägeloh-Mann, I. Increases in language lateralization in normal children as observed using magnetoencephalography. Brain Lang. 2008, 106, 167-176. [CrossRef]

40. Esseily, R.; Jacquet, A.Y.; Fagard, J. Handedness for grasping objects and pointing and the development of language in 14-monthold infants. Lateral 2011, 16, 565-585. [CrossRef]

41. Mumford, K.H.; Kita, S. At 10-12 months, pointing gesture handedness predicts the size of receptive vocabularies. Infancy 2016, 21,751-765. [CrossRef]

42. Nicoladis, E.; Dueck, B.S.; Zarezadehkheibari, S. Hand preference in referential gestures: Relationships to accessing words for speaking in monolingual and bilingual children. Brain Behav. 2021, 11, e02121. [CrossRef] [PubMed]

43. Hiscock, M.; Israelian, M.; Inch, R.; Jacek, C.; Hiscock-Kalil, C. Is there a sex difference in human laterality? An exhaustive survey of visual laterality studies from six neuropsychology journals. J. Clin. Exp. Neuropsy. 1995, 17, 590-610. [CrossRef] [PubMed]

44. Kansaku, K.; Yamaura, A.; Kitazawa, S. Sex differences in lateralization revealed in the posterior language areas. Cereb. Cort. 2000, 9, 866-872. [CrossRef]

45. Yu, V.Y.; MacDonald, M.J.; Oh, A.; Hua, G.N.; De Nil, L.F.; Pang, E.W. Age-related sex differences in language lateralization: A magnetoencephalography study in children. Dev. Psy. 2014, 50, 2276-2284. [CrossRef]

46. Sommer, I.E.; Aleman, A.; Somers, M.; Boks, M.P.; Kahn, R.S. Sex differences in handedness, asymmetry of the planum temporale and functional language lateralization. Brain Res. 2008, 1206, 76-88. [CrossRef]

47. Kavé, G.; Gavrieli, R.; Mashal, N. Stronger left-hemisphere lateralization in older versus younger adults while processing conventional metaphors. Lateral 2014, 19, 705-717. [CrossRef]

48. Aziz, J.R.; Nicoladis, E. My French is rusty: Proficiency and bilingual gesture use in a majority English community. Biling Lang. Cog. 2019, 22, 826-835. [CrossRef]

49. Smithson, L.; Nicoladis, E. Verbal memory resources predict iconic gesture use among bilinguals and monolinguals. Biling Lang. Cog. 2013, 16, 934-944. [CrossRef]

50. Dunn, L.M.; Dunn, L.M. Peabody Picture Vocabulary Test, 3rd ed.; American Guidance Service: Circle Pines, MN, USA, 1997.

51. Dunn, L.M.; Dunn, L.M.; Thériault-Whalen, C.M. Échelle de Vocabulaire en Images Peabody: EVIP; Psycan: Toronto, ON, Canada, 1993.

52. Lavergne, J.; Kimura, D. Hand movement asymmetry during speech: No effect of speaking topic. Neuropsychology 1987, 25, 689-693. [CrossRef]

53. Ocklenburg, S.; Beste, C.; Arning, L.; Peterburs, J.; Güntürkün, O. The ontogenesis of language lateralization and its relation to handedness. Neurosci. Biobehav. Rev. 2014, 43, 191-198. [CrossRef] [PubMed]

54. Prichard, E.; Propper, R.E.; Christman, S.D. Degree of handedness, but not direction, is a systematic predictor of cognitive performance. Front. Psych. 2013, 4, 9. [CrossRef]

55. Coren, S. The lateral preference inventory for measurement of handedness, footedness, eyedness, and earedness: Norms for young adults. Bull. Psychonom. Soc. 1993, 31, 1-3. [CrossRef]

56. Papadatou-Pastou, M.; Martin, M.; Munafò, M.R.; Jones, G.V. Sex differences in left-handedness: A meta-analysis of 144 studies. Psych. Bull. 2008, 134, 677-699. [CrossRef]

57. Garcea, F.E.; Almeida, J.; Mahon, B.Z. A right visual field advantage for visual processing of manipulable objects. Cog. Aff. Beh. Neurosci. 2012, 12, 813-825. [CrossRef]

58. Van der Cruyssen, I.; Gerrits, R.; Vingerhoets, G. The right visual field advantage for word processing is stronger in older adults. Brain Lang. 2020, 205, 104786. [CrossRef] [PubMed] 